\title{
Minimally Invasive Lumbar Spinal Decompression in Elderly Patients with Magnetic Resonance Imaging Morphological Analysis
}

\author{
Seungman $\mathrm{Ha}^{1}$, Youngho Hong ${ }^{2}$, Seungcheol Lee ${ }^{2}$ \\ ${ }^{I}$ Department of Neurosurgery, Chungbuk National University Hospital, Cheongju, Korea \\ ${ }^{2}$ Department of Neurosurgery, Barunsesang Hospital, Seongnam, Korea
}

\begin{abstract}
Study Design: Case-control study.
Purpose: In this study, we aimed to investigate clinical outcomes and morphological features in elderly patients with lumbar spinal stenosis (LSS) who were treated by minimally invasive surgery (MIS) unilateral laminectomy for bilateral decompression (ULBD) using a tubular retractor.

Overview of Literature: Numerous methods using imaging have been attempted to describe the severity of spinal stenosis. But the relationship between clinical symptoms and radiological features remains debatable.

Objective: In this study, we aimed to investigate clinical outcomes and morphological features in elderly patients with LSS who were treated by MIS-ULBD

Methods: We methodically assessed 85 consecutive patients aged $>65$ years who were treated for LSS. The patients were retrospectively analyzed in two age groups: 66-75 years (group 1) and $>75$ years (group 2). Clinical outcomes were assessed using the Visual Analog Scale (VAS), Oswestry Disability Index (ODI), and the modified MacNab criteria. Outcome parameters were compared between the groups at the 1-year follow-up. Core radiologic parameters for central and lateral stenosis were analyzed and clinical findings of the groups were compared.

Results: At the 1-year follow-up, patients in both groups 1 and 2 demonstrated significant improvement in their VAS and ODI scores. All clinical outcomes, except postoperative ODI, were not significantly difference between the groups. In addition, no significant difference was noted in the preoperative radiological parameters between the groups. There was no statistically significant correlation between radiological parameters and clinical symptoms or their outcomes. Moreover, no differences were noted in perioperative adverse events and in the need for repeat surgery at follow-ups between the groups.

Conclusions: MIS-ULBD by tubular approach is a safe and effective treatment option for elderly patients with LSS. Clinical outcomes in patients with LSS and aged $>75$ years were comparable with those in patients with LSS and aged $66-75$ years. Moreover, we did not find any correlation between radiological parameters and clinical outcomes in either of the two patient groups.
\end{abstract}

Keywords: Spine; Spinal stenosis; Laminectomy; Aged; Anatomy

Received Jun 13, 2017; Revised Sep 11, 2017; Accepted Sep 16, 2017

Corresponding author: Seungcheol Lee

Department of Neurosurgery, Dr. Lee’s Spine Hospital, 2nd floor, 11 Seongnam-daero 925beon-gil, Bundang-gu, Seongnam 13497, Korea

Tel: +82-31-701-1190, Fax: +82-31-701-1199, E-mail: bestspine@gmail.com 


\section{Introduction}

In an aging society, an increase in the occurrence of lumbar degenerative diseases, including lumbar spinal stenosis (LSS), is unavoidable [1]. LSS is one of the most common cause of lumbar spine surgery in patients aged $>65$ years. LSS decreases the quality of life and in severe cases, presents with problems in activities of daily living among elderly patients with radiculopathy and neurogenic intermittent claudication. In addition, the use of drug-based and non-operative treatments may fail to result in improvement and satisfaction in some patients. Decompression surgery, with or without fusion or devices, is more effective than continued conservative treatment, when the latter is not successful in patients with symptomatic LSS [2]. A recent randomized controlled trial demonstrated that a combination of decompression and fusion surgery does not result in better clinical outcomes at 2- and 5-year follow-up than decompression surgery alone [3].

Deyo et al. [4] reported that age is positively correlated with complication rates in patients treated by standard open laminectomy. However, minimally invasive surgery (MIS), which decreases the physiological burden of a surgery, can particularly benefit the elderly population by reducing the surgical risk associated with preoperative morbidity and postoperative immobility [5]. MIS techniques such as unilateral laminectomy for bilateral decompression (ULBD) for LSS have shown better clinical outcomes and have been widely used in comparison to conventional open laminectomy $[5,6]$.

Although magnetic resonance imaging (MRI) is broadly used in establishing the diagnosis of LSS, the relationship between clinical symptoms and radiological features remains debatable [7]. Numerous methods using imaging have been attempted to describe the severity of spinal stenosis $[8,9]$. However, to the best of our knowledge, there is no published literature thus far that deals with the discussed characteristics in the elderly using recent core parameters chosen in the consensus conference [10].

The purpose of this study was to report clinical results of MIS-ULBD in a single institution to contribute to the evidence base of the effectiveness of ULBD in elderly patients with LSS. We have also described morphological characteristics according to age and the relationship between magnetic resonance (MR) parameters and symptom or outcomes.

\section{Materials and Methods}

\section{Patient selection}

A total of 555 subjects were treated with ULBD at Barunsesang Hospital from April 2014 to January 2016. To avoid surgeon bias, we included 357 patients who were operated by the senior author (SL) for analysis in this study. We excluded 139 patients who concurrently underwent additional surgeries, such as discectomy, foraminal decompression, screw removal, or fusion. We also excluded 115 patients aged $<65$ years. Finally, 85 patients who successfully completed the 1-year follow-up were included in the study. Patients were divided based on their age (group 1: $<65$ years, $n=52$ and group 2: $>65$ years, $n=33$ ). Informed consent was provided by all patients or their family members under an approved Institutional Review Board protocol.

Our sample included patients who were unresponsive to non-operative conservative treatment for at least 12 weeks and who showed progressive symptoms despite continued non-operative treatment. The exclusion criteria included patients with marked neuroforaminal stenosis (treated by fusion or foraminal decompression at our in-

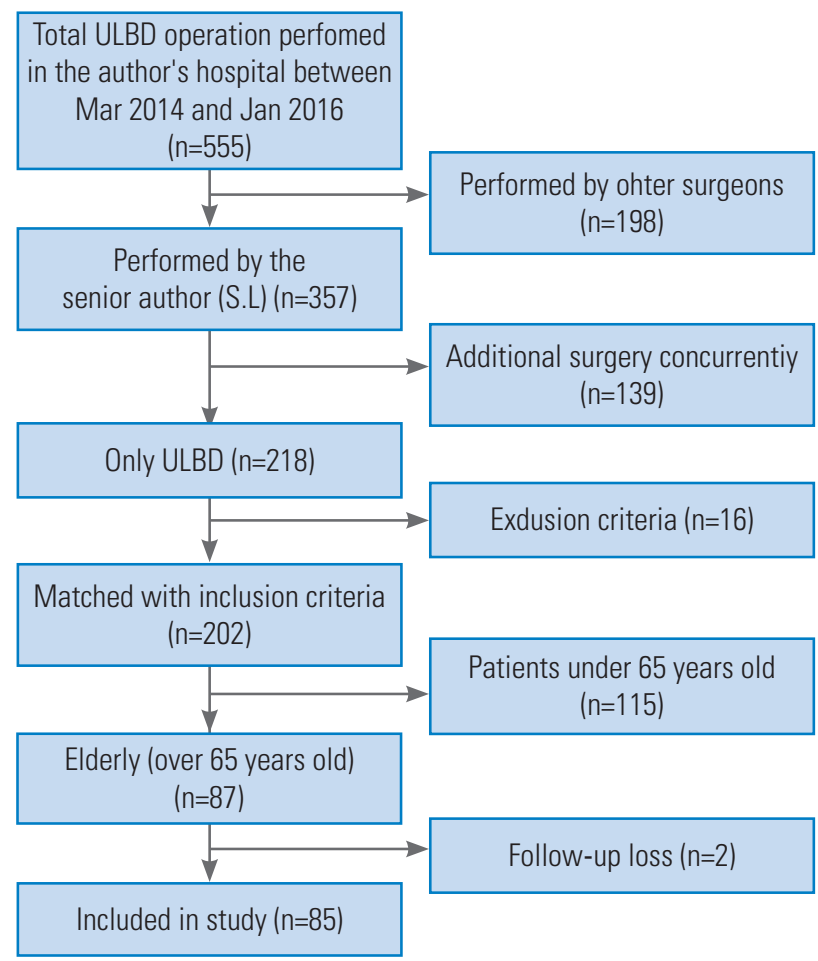

Fig. 1. Flowchart showing the patient selection process. ULBD, unilateral laminectomy for bilateral decompression. 
stitution, described elsewhere) [11], over three levels of stenosis (treated by spinous process splitting laminectomy at our institution, described elsewhere) [12], any prior spine surgery at any operative level in consideration of morphological changes, any prior lumbar fusion at any level to avoid adjacent disc disease, or requiring additional concurrent treatments. Patients with segmental instability, lytic spondylolisthesis, and degenerative spondylolisthesis over grade 2, with predominant lower-back pain were also excluded from the study. Only selected patients with lumbar spinal central or lateral stenosis treated by ULBD were included in the present study (Fig. 1).

\section{Clinical assessment}

Demographic, preoperative, and postoperative data were collected from patients' medical records. Preoperative and postoperative patient-reported outcome parameters included Visual Analog Scale (VAS) scores, Oswestry Disability Index (ODI), and MacNab grade. VAS scores for leg pain and ODI scores were collected preoperatively and on the day of the 1-year follow-up. The MacNab grade for functional improvement was noted for all patients at the time of their 1-year follow-up. Global outcomes and patient satisfaction were assessed by using modified MacNab criteria (excellent, good, fair, and poor).

\section{Imaging analysis}

Two observers independently measured the diagnostic parameters. For each parameter, we used the average of the two observers' measurements. A difference in grading was observed in two cases and was solved in consensus. Preoperative and postoperative imaging studies (anterior- posterior and lateral flexion-extension radiographs, sagittal and axial computed tomography, and sagittal and axial T1W and T2W MRI) were methodically assessed for the degree of spondylolisthesis and presence or absence of segmental instability and scoliosis based on the exclusion criteria. The dural sac anteroposterior diameter, dural sac cross-sectional area (DSCSA), lateral recess height, compromise of the central zone [13], and nerve root compression in the lateral recess [14] were included in the analysis according to the consensus conference on core radiological parameters to describe lumbar stenosis [10] (Fig. 2). The most constricted level was selected for analysis in patients affected at a double level. These parameters were measured using a measuring program with a builtin picture archiving communication system (PiView; INFINITT Co. Ltd., Seoul, Korea).

\section{Surgical techniques}

In the present study, the surgery was performed under epidural anesthesia in $95 \%$ cases (81/85). Four patients underwent surgery under general or spinal anesthesia based on the decision of the anesthesiologist. During surgery, the patients were placed in a prone position on a Wilson frame. After identification of the operation level under fluoroscopic guidance, the incision site was marked on the inferior part of the lamina immediately above the index disc level, which was approximately $1 \mathrm{~cm}$ away from the midline. Surgery was performed in a mini-open fashion with 16-mm working tubes (MetRx; Medtronic Sofamor Danek, Memphis, TN, USA) using a skin incision of approximately $1.8 \mathrm{~cm}$. After introducing a tubular retractor over the index lamina perpendicular, laminectomy was performed using a high-speed diamond drill and Kerrison
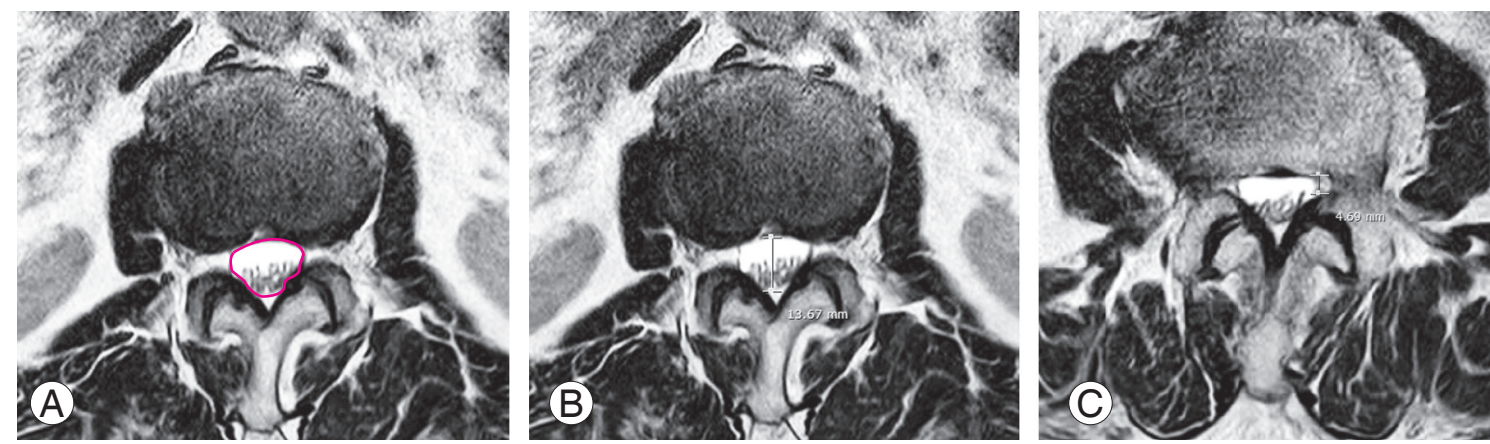

Fig. 2. Illustrations of dural sac cross-sectional area (A), dural sac anterior-posterior diameter (B), and lateral recess height (C) on axial T2-weighted images. 
rongeurs for decompression of the ipsilateral exiting roots. Decompression was usually performed clockwise and was followed by continued decompression of the ipsilateral lateral recess for identifying the traversing root. Then, the roof of the spinal canal was undercut. Hence, contralateral traversing nerve roots were also visualized and decom-
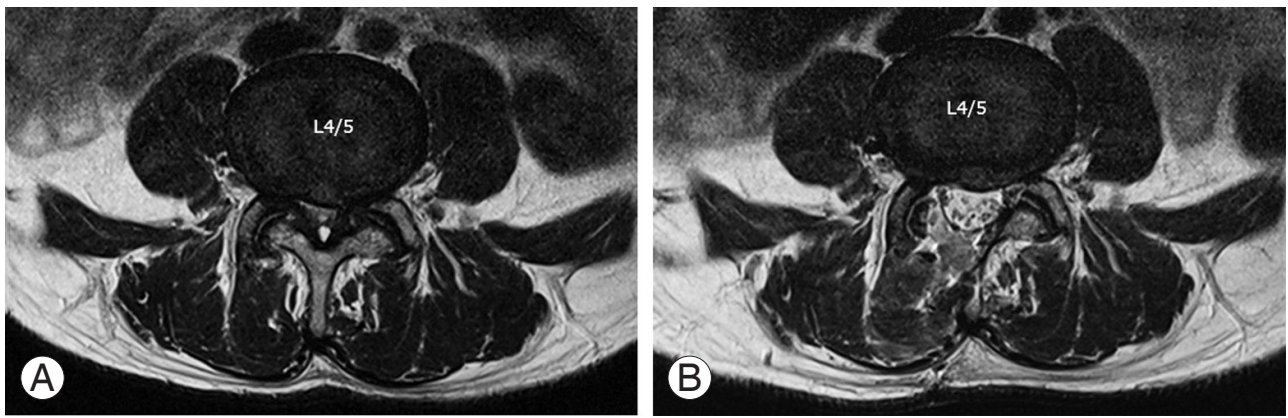

Fig. 3. Representative preoperative (A) and postoperative (B) magnetic resonance imaging images of a patient.

Table 1. Clinical outcomes of minimally invasive unilateral laminectomy for bilateral decompression by tubular retractor

\begin{tabular}{|c|c|c|c|c|}
\hline Characteristic & Total ( $N=85)$ & Group $1(n=52)$ & Group 2 (n=33) & $p$-value \\
\hline Age at surgery (yr) & $73.80 \pm 5.24$ & $70.40 \pm 2.90$ & $79.15 \pm 3.35$ & 0.000 \\
\hline Sex & & & & 0.026 \\
\hline Male & 31 & 14 & 17 & \\
\hline Female & 54 & 38 & 16 & \\
\hline Body mass index $\left(\mathrm{kg} / \mathrm{m}^{2}\right)$ & $24.20 \pm 3.51$ & $24.96 \pm 3.08$ & $22.99 \pm 3.88$ & 0.011 \\
\hline Follow-up (mo) & $22.07 \pm 5.62$ & $22.25 \pm 6.00$ & $21.78 \pm 5.13$ & 0.716 \\
\hline Modified frailty index & $1.06 \pm 0.77$ & $1.00 \pm 0.82$ & $1.14 \pm 0.68$ & 0.415 \\
\hline Diabetes & 23 & 16 & 7 & 0.340 \\
\hline Hypertension & 59 & 35 & 24 & 0.602 \\
\hline Affected level & & & & 0.246 \\
\hline Single level & 58 & 38 & 20 & \\
\hline Double levels & 27 & 14 & 13 & \\
\hline Single level & & & & 0.774 \\
\hline $\mathrm{L} 2 / 3$ & 1 & 1 & 0 & \\
\hline $\mathrm{L} 3 / 4$ & 4 & 2 & 2 & \\
\hline$\llcorner 4 / 5$ & 51 & 34 & 17 & \\
\hline L5/S1 & 2 & 1 & 1 & \\
\hline Double levels & & & & 0.275 \\
\hline$L 2 / 3 \& L 4 / 5$ & 2 & 0 & 2 & \\
\hline$L 3 / 4 \& L 4 / 5$ & 18 & 11 & 7 & \\
\hline L4/5 \& L5/S1 & 6 & 2 & 4 & \\
\hline $\mathrm{L} 3 / 4 \& \mathrm{~L} 5 / \mathrm{S} 1$ & 1 & 1 & 0 & \\
\hline Neurogenic intermittent claudication (m) & & & & 0.233 \\
\hline$<50$ & 10 & 5 & 5 & \\
\hline $50-250$ & 41 & 22 & 19 & \\
\hline $250-1,000$ & 14 & 10 & 4 & \\
\hline$>1,000$ & 20 & 15 & 5 & \\
\hline
\end{tabular}

Values are presented as mean \pm standard deviation or number. 
pressed after drilling of the contralateral lateral recess. Subsequently, the contralateral exiting roots were identified and decompressed. After massive irrigation, an antiadhesive agent was applied over the thecal sac. Finally, the surgical wound was closed layer by layer (Fig. 3, Video 1).

\section{Statistical analysis}

For statistical analysis, the paired sample $t$-test, independent sample $t$-test for group comparisons, Fisher's exact test for categorical comparison, and Pearson's correlation coefficient for assessing the relationship between radiological parameters and clinical outcomes were conducted using IBM SPSS ver. 21.0 (IBM Corp., Armonk, NY, USA). All $p<0.05$ were considered to be statistically significant.

\section{Results}

A total of 85 patients were included in the study whose characteristics are described in Table 1. Mean ages at the time of surgery were $73.80,70.40$, and 79.15 years for group 1+group 2, group 1, and group 2, respectively. The most common level of spinal stenosis was the L4-L5 segment. Although sex distribution and body mass index (BMI) were significantly different between the groups, preoperative risk factors were similar.

VAS and ODI scores showed significant improvement at the 1-year postoperative follow-up in both groups $(p<0.05$ and $p<0.05$, respectively); no significant differences were noted in VAS and ODI scores between the groups, except the postoperative ODI which was greater in group 1 than in group 2 . The MacNab's grade was not significantly different between the two groups ( $p=0.525$ ) (Table 2).

The radiological parameters are presented in Table 3. The preoperative parameters were not significantly different on group comparisons. In addition, the degree of both central and lateral stenosis did not show any difference with respect to the age group. Moreover, radiological parameters were not correlated to symptoms (Table 4).

The preoperative results, including the surgical time, hospital stay duration, blood loss, and hospital charges were not significantly different between the groups (Table 5). In addition, no differences were noted in the preoperative adverse events between the groups. Finally, no major complications, deaths, or infections occurred in the study (Table 6).

\section{Discussion}

Shamji et al. [15] retrospectively reviewed the efficiency

Table 2. Clinical outcomes of minimally invasive unilateral laminectomy for bilateral decompression by tubular retractor

\begin{tabular}{|c|c|c|c|c|}
\hline Variable & Total & Group $1(\mathrm{n}=52)$ & Group 2 (n=33) & $p$-value \\
\hline \multicolumn{5}{|c|}{ Visual Analog Scale } \\
\hline Preoperative & $6.94 \pm 0.83$ & $6.94 \pm 0.82$ & $6.93 \pm 0.86$ & 0.988 \\
\hline Postoperative & $3.14 \pm 1.46$ & $3.00 \pm 1.52$ & $3.36 \pm 1.38$ & 0.270 \\
\hline Recovery & $3.80 \pm 1.62$ & $3.94 \pm 1.57$ & $3.57 \pm 1.71$ & 0.316 \\
\hline$p$-value & 0.000 & 0.000 & 0.000 & \\
\hline \multicolumn{5}{|c|}{ Oswestry Disability Index } \\
\hline Preoperative & $49.58 \pm 7.90$ & $48.65 \pm 7.42$ & $51.03 \pm 8.63$ & 0.181 \\
\hline Postoperative & $31.44 \pm 7.58$ & $30.11 \pm 7.55$ & $33.51 \pm 7.39$ & 0.045 \\
\hline Recovery & $18.14 \pm 8.18$ & $18.53 \pm 9.07$ & $17.51 \pm 6.78$ & 0.580 \\
\hline$p$-value & 0.000 & 0.000 & 0.000 & \\
\hline MacNab's grade & & & & $0.525^{\text {a) }}$ \\
\hline Excellent & 11 & 8 & 3 & \\
\hline Good & 31 & 21 & 10 & \\
\hline Fair & 33 & 18 & 15 & \\
\hline Poor & 10 & 5 & 5 & \\
\hline
\end{tabular}

Values are presented as mean \pm standard deviation or number, unless otherwise stated.

a)By Fisher's exact test. 
Table 3. Radiological parameters of elderly patients with lumbar spinal stenosis

\begin{tabular}{|c|c|c|c|c|}
\hline Variable & Total & Group $1(\mathrm{n}=52)$ & Group $2(n=33)$ & $p$-value \\
\hline Dural sac cross-sectional area $\left(\mathrm{cm}^{2}\right)$ & $0.64 \pm 0.33$ & $0.63 \pm 0.36$ & $0.58 \pm 0.28$ & 0.189 \\
\hline Dural sac anterior-posterior diameter (mm) & $7.33 \pm 1.83$ & $7.28 \pm 1.89$ & $7.40 \pm 1.79$ & 0.784 \\
\hline Lateral recess height (mm) & $2.53 \pm 0.86$ & $2.59 \pm 0.80$ & $2.40 \pm 0.95$ & 0.328 \\
\hline Central compression & & & & $0.340^{a)}$ \\
\hline Grade A & 4 & 2 & 2 & \\
\hline Grade B & 28 & 18 & 10 & \\
\hline Grade C & 28 & 20 & 8 & \\
\hline Grade D & 25 & 12 & 13 & \\
\hline Lateral compression & & & & $0.882^{a)}$ \\
\hline Grade 0 & 0 & 0 & 0 & \\
\hline Grade1 & 6 & 4 & 2 & \\
\hline Grade 2 & 28 & 16 & 12 & \\
\hline Grade 3 & 41 & 32 & 19 & \\
\hline
\end{tabular}

Values are presented as mean \pm standard deviation or number, unless otherwise stated.

alBy Fisher's exact test.

Table 4. Pearson's correlation between radiological parameters and clinical symptoms or outcomes

\begin{tabular}{|c|c|c|c|c|c|c|c|c|c|c|}
\hline \multirow[t]{2}{*}{ Variable } & \multicolumn{2}{|c|}{$\begin{array}{l}\text { Preoperative } \\
\text { ODI }\end{array}$} & \multicolumn{2}{|c|}{$\begin{array}{l}\text { ODI } \\
\text { improvement }\end{array}$} & \multicolumn{2}{|c|}{$\begin{array}{c}\text { Preoperative } \\
\text { VAS }\end{array}$} & \multicolumn{2}{|c|}{$\begin{array}{c}\text { VAS } \\
\text { improvement }\end{array}$} & \multicolumn{2}{|c|}{$\begin{array}{c}\text { Neurogenic intermittent } \\
\text { claudication }\end{array}$} \\
\hline & $r$ & $p$-value & $r$ & $p$-value & $r$ & $p$-value & $r$ & $p$-value & $r$ & $p$-value \\
\hline Dural sac cross-sectional area & -0.025 & 0.820 & 0.016 & 0.885 & 0.082 & 0.457 & 0.091 & 0.408 & 0.086 & 0.436 \\
\hline Dural sac anterior-posterior diameter & 0.029 & 0.789 & -0.067 & 0.545 & 0.165 & 0.131 & 0.115 & 0.294 & 0.092 & 0.401 \\
\hline Lateral recess height & 0.009 & 0.934 & 0.059 & 0.593 & 0.044 & 0.687 & 0.143 & 0.191 & 0.022 & 0.839 \\
\hline Central compression & 0.062 & 0.571 & 0.048 & 0.665 & -0.101 & 0.926 & -0.042 & 0.701 & -0.138 & 0.208 \\
\hline Lateral compression & -0.117 & 0.288 & -0.061 & 0.581 & -0.076 & 0.490 & -0.081 & 0.460 & 0.014 & 0.900 \\
\hline
\end{tabular}

ODI, Oswestry Disability Index; VAS, Visual Analog Scale.

Table 5. Perioperative results of minimally invasive unilateral laminectomy for bilateral decompression by tubular retractor

\begin{tabular}{|c|c|c|c|c|}
\hline Variable & Total & Group 1 (n=52) & Group 2 (n=33) & $p$-value \\
\hline Operative time (min) & $61.24 \pm 22.14$ & $62.59 \pm 20.94$ & $59.09 \pm 24.41$ & 0.483 \\
\hline Single level & $51.89 \pm 14.13$ & $54.34 \pm 15.07$ & $47.25 \pm 11.25$ & 0.071 \\
\hline No. of patients & 58 & 38 & 20 & \\
\hline Double level & $81.29 \pm 22.91$ & $85.00 \pm 18.29$ & $77.30 \pm 28.03$ & 0.403 \\
\hline No. of patients & 27 & 14 & 13 & \\
\hline Blood loss (mL) & $42.71 \pm 24.36$ & $43.50 \pm 23.82$ & $41.45 \pm 25.86$ & 0.710 \\
\hline Mean length of stay (day) & $3.41 \pm 1.57$ & $3.38 \pm 1.33$ & $3.45 \pm 1.93$ & 0.844 \\
\hline Mean hospital charges ${ }^{a}$ W $\mathbb{( \$ )}$ & $4,951,866(4,100.25)$ & $\begin{array}{r}5,033,498 \pm 849,861 \\
(4,167.83 \pm 703.70)\end{array}$ & $\begin{array}{c}4,823,234 \pm 804,024 \\
(3,993.73 \pm 665.74)\end{array}$ & 0.260 \\
\hline
\end{tabular}

Values are presented as mean \pm standard deviation or number, unless otherwise stated.

${ }^{a}$ The won-dollar exchange rate was calculated as an average of $2016(\$ 1=W 1,207.7)$. 
Table 6. Perioperative adverse events in the two age groups

\begin{tabular}{lccl} 
Age group & $\begin{array}{c}\text { No. of patients with } \\
\text { adverse events }\end{array}$ & Adverse events & $\begin{array}{c}\text { Need for repeat surgery } \\
\text { at follow-up }\end{array}$ \\
Group 1: $66-75$ yr $(n=52)$ & 9 & $\begin{array}{c}\text { Dura tear }(n=6) \text {, permanent motor weakness }(n=1) \text {, tran- } \\
\text { sient motor weakness }(n=1) \text {, wound dehiscence }(n=1)\end{array}$ & 3 \\
Group 2: $>75$ yr $(n=33)$ & 6 & $\begin{array}{c}\text { Transient weakness }(n=3) \text {, postop neuropathic pain }(n=2), \\
\text { dura tear }(n=1)\end{array}$ & 4 \\
\hline$p$-value & 0.919 & & 0.342 \\
\hline
\end{tabular}

and safety of LSS in elderly and recommended that surgical intervention should be considered even in elderly patients. Other studies reported favorable clinical outcomes in octogenarians [16] and multilevel-affected patients [17], although patients with diabetes mellitus [18] or high BMI $\left(>30 \mathrm{~kg} / \mathrm{m}^{2}\right)$ [17] were reported to show negative prognostic factors after surgical intervention. In our study, patients aged $>75$ years presented with clinical outcomes that were comparable with that of younger patients with similar risk factors of the underlying disease, as measured by the modified frailty index. In general, the operating surgeon should be considerate of the life expectancy at a given age, but advanced age per se is not a contraindication for decompressive surgery.

Although the usage of the MIS technique for spinal stenosis has increased, it is relatively scarcely used in elderly patients [5]. Rosen et al. [19] prospectively investigated 57 patients aged $>75$ years and reported improvements in VAS and ODI scores without any major complications. Aleem and Rampersaud [20] found similar outcomes on comparing these scores between elderly patients (age $>70$ years) and younger patients (age $<70$ years). Various procedures, including foraminotomy, performed by Rosen et al. [19] and Aleem and Rampersaud [20], resulted in decompression-only or in decompression and fusion. We performed minimally invasive decompression-only in elderly patients with focal (1-2 level) LSS using a tubular retractor microscopy-assisted surgery for ULBD.

Among the various MIS techniques known for LSS, such as percutaneous biportal endoscopic decompression, or full endoscopic procedures, we selected MIS-ULBD using a tubular retractor (first described by Spetzger et al. [21]) and through the tubular approach suggested by Parmer [22]. ULBD for LSS showed better outcomes than conventional laminectomy $[23,24]$. Cavusoglu et al. [25] also reported favorable mid-term outcomes after ULBD for LSS in their 5-year prospective study. Although asym- metric decompression may be worrisome according to the unilateral approach, Alimi et al. [26] affirms that ipsilateral and contralateral symptoms can be effectively treated by this method.

We performed volumetric access to discover the relationship between MR parameters and the severity of symptoms and their outcomes. In few previous studies, several MRI parameters were measured for evaluating the severity of spinal stenosis. However, the relationship between MRI findings and symptoms remained unclear [8]. Recently, Burgstaller et al. [7] conducted a systematic literature review and analyzed the relationship between MRI parameters and pain in 150 patients with LSS and found no correlation. In addition, no significant correlations were noted between preoperative DSCSA and clinical symptoms in patients treated by ULBD [27]. Similar results were also demonstrated in the present study.

We hypothesized that at least central stenosis would be severe in the older groups because it is a degenerative change. However, in our study, central or lateral stenosis was not frequent or severe in any specific age group. In addition, no statistically significant correlation existed with respect to any parameters for clinical symptoms or outcomes. In the literature, patients with degenerative LSS rarely manifested cauda equina syndrome. In the present study, no patient complained of saddle anesthesia, bladder and bowel dysfunction, or definite motor weakness, despite manifesting severe stenosis on MRI. Thus, we believe that the use of MR parameters is inadequate for evaluating the severity of spinal stenosis.

Various factors associated with the limitations of MR or the characteristics of LSS per se could have influenced these results. First, cross-sectional imaging is insufficient for evaluating spinal stenosis. Bartynski and Lin [14] reported inferiority of MRI compared with CT with myelography owing to the difficulty in measuring uniformly depending on the situation. Compared with high intra- 
observer reliability, the inter-observer reliability is low [13]. Second, most patients with spinal stenosis show some degree of accompanying disc protrusion. The sudden expansion of disc protrusion may trigger symptoms in some patients through compression delivered at a rapid onset rate [28]. In these cases, nerve entrapment may induce sudden onset of pain rather than chronic shifting and late compression. Third, congenital morphological feasibility is also a feasible reason. The trefoil configuration showed high incidence and vulnerability for LSS in some studies [14]. Fourth, the spinal canal is a dynamic structure, and the diameters vary due to changing postures and body activities. Consequently, a static image of the lumbar canal in the supine position may not represent dimensions of the spinal canal during activity [9]. Fifth, hemodynamics in the spinal region assumes a certain role in the symptoms. Some evidence supports the thesis that obstruction of the blood circulation is causal for the intermittent character of pain [29]. Finally, conventional MR cannot evaluate the nerve function that may be assessed by new imaging modalities, such as high-resolution MR neurography or diffusion tensor imaging [30].

There are some limitations of the present study. This was a retrospective, uncontrolled review of clinical outcomes in a single institution. Our study included a rather short follow-up. With respect to patient demographics, the younger group showed significantly higher BMI than the older group; this was believed to be associated with senile sarcopenia and the fact that sex distribution was significantly different.

\section{Conclusions}

MIS-ULBD by a tubular approach is a safe and effective treatment option for elderly patients with LSS. Clinical outcomes of patients aged $>75$ years were comparable to those of 66-75-year-old patients with LSS. We could not find any correlation between radiological parameters and clinical findings.

\section{Conflict of Interest}

No potential conflict of interest relevant to this article was reported.

\section{Supplementary Materials}

Supplementary materials can be found via https://www. youtube.com/watch? $=2 \mathrm{kpJRAe} 2 \mathrm{H} 2 \mathrm{U}$. Video 1 . Unilateral laminectomy for bilateral decompression using a tubular retractor for lumbar spinal stenosis.

\section{References}

1. Fehlings MG, Tetreault L, Nater A, et al. The aging of the global population: the changing epidemiology of disease and spinal disorders. Neurosurgery 2015;77 Suppl 4:S1-5.

2. Kovacs FM, Urrutia G, Alarcon JD. Surgery versus conservative treatment for symptomatic lumbar spinal stenosis: a systematic review of randomized controlled trials. Spine (Phila Pa 1976) 2011;36:E133551.

3. Forsth P, Olafsson G, Carlsson T, et al. A randomized, controlled trial of fusion surgery for lumbar spinal stenosis. N Engl J Med 2016;374:1413-23.

4. Deyo RA, Cherkin DC, Loeser JD, Bigos SJ, Ciol MA. Morbidity and mortality in association with operations on the lumbar spine: the influence of age, diagnosis, and procedure. J Bone Joint Surg Am 1992;74:536-43.

5. Shamji MF, Goldstein CL, Wang M, Uribe JS, Fehlings MG. Minimally invasive spinal surgery in the elderly: does it make sense? Neurosurgery 2015;77 Suppl 4:S108-15.

6. Phan K, Mobbs RJ. Minimally invasive versus open laminectomy for lumbar stenosis: a systematic review and meta-analysis. Spine (Phila Pa 1976) 2016;41:E91-E100.

7. Burgstaller JM, Schuffler PJ, Buhmann JM, et al. Is there an association between pain and magnetic resonance imaging parameters in patients with lumbar spinal stenosis? Spine (Phila Pa 1976) 2016;41:E105362.

8. Sigmundsson FG, Kang XP, Jonsson B, Stromqvist B. Correlation between disability and MRI findings in lumbar spinal stenosis: a prospective study of 109 patients operated on by decompression. Acta Orthop 2011;82:204-10.

9. Kim HJ, Suh BG, Lee DB, et al. The influence of pain sensitivity on the symptom severity in patients with lumbar spinal stenosis. Pain Physician 2013;16:135- 
44.

10. Andreisek G, Deyo RA, Jarvik JG, et al. Consensus conference on core radiological parameters to describe lumbar stenosis: an initiative for structured reporting. Eur Radiol 2014;24:3224-32.

11. Lee S, Kang JH, Srikantha U, Jang IT, Oh SH. Extraforaminal compression of the L-5 nerve root at the lumbosacral junction: clinical analysis, decompression technique, and outcome. J Neurosurg Spine 2014;20:371-9.

12. Lee S, Srikantha U. Spinous process splitting laminectomy: clinical outcome and Radiological analysis of extent of decompression. Int J Spine Surg 2015;9:20.

13. Schizas C, Theumann N, Burn A, et al. Qualitative grading of severity of lumbar spinal stenosis based on the morphology of the dural sac on magnetic resonance images. Spine (Phila Pa 1976) 2010;35:191924.

14. Bartynski WS, Lin L. Lumbar root compression in the lateral recess: MR imaging, conventional myelography, and CT myelography comparison with surgical confirmation. AJNR Am J Neuroradiol 2003;24:34860.

15. Shamji MF, Mroz T, Hsu W, Chutkan N. Management of degenerative lumbar spinal stenosis in the elderly. Neurosurgery 2015;77 Suppl 4:S68-74.

16. Nanjo Y, Nagashima H, Dokai T, et al. Clinical features and surgical outcomes of lumbar spinal stenosis in patients aged 80 years or older: a multicenter retrospective study. Arch Orthop Trauma Surg 2013;133:1243-8.

17. Papavero L, Thiel M, Fritzsche E, Kunze C, Westphal M, Kothe R. Lumbar spinal stenosis: prognostic factors for bilateral microsurgical decompression using a unilateral approach. Neurosurgery 2009;65(6 Suppl):182-7.

18. Arinzon Z, Adunsky A, Fidelman Z, Gepstein R. Outcomes of decompression surgery for lumbar spinal stenosis in elderly diabetic patients. Eur Spine J 2004;13:32-7.

19. Rosen DS, O’Toole JE, Eichholz KM, et al. Minimally invasive lumbar spinal decompression in the elderly: outcomes of 50 patients aged 75 years and older. Neurosurgery 2007;60:503-9.

20. Aleem IS, Rampersaud YR. Elderly patients have similar outcomes compared to younger patients after minimally invasive surgery for spinal stenosis. Clin
Orthop Relat Res 2014;472:1824-30.

21. Spetzger U, Bertalanffy H, Naujokat C, von Keyserlingk DG, Gilsbach JM. Unilateral laminotomy for bilateral decompression of lumbar spinal stenosis: part I: anatomical and surgical considerations. Acta Neurochir (Wien) 1997;139:392-6.

22. Palmer S, Turner R, Palmer R. Bilateral decompression of lumbar spinal stenosis involving a unilateral approach with microscope and tubular retractor system. J Neurosurg 2002;97(2 Suppl):213-7.

23. Usman M, Ali M, Khanzada K, et al. Unilateral approach for bilateral decompression of lumbar spinal stenosis: a minimal invasive surgery. J Coll Physicians Surg Pak 2013;23:852-6.

24. Yagi M, Okada E, Ninomiya K, Kihara M. Postoperative outcome after modified unilateral-approach microendoscopic midline decompression for degenerative spinal stenosis. J Neurosurg Spine 2009;10:293-9.

25. Cavusoglu H, Kaya RA, Turkmenoglu ON, Tuncer C, Colak I, Aydin Y. Midterm outcome after unilateral approach for bilateral decompression of lumbar spinal stenosis: 5-year prospective study. Eur Spine J 2007;16:2133-42.

26. Alimi M, Hofstetter CP, Torres-Campa JM, et al. Unilateral tubular approach for bilateral laminotomy: effect on ipsilateral and contralateral buttock and leg pain. Eur Spine J 2017;26:389-96.

27. Chung SW, Kang MS, Shin YH, Baek OK, Lee SH. Postoperative expansion of dural sac cross-sectional area after unilateral laminotomy for bilateral decompression: correlation with clinical symptoms. Korean J Spine 2014;11:227-31.

28. Olmarker K, Holm S, Rydevik B. Importance of compression onset rate for the degree of impairment of impulse propagation in experimental compression injury of the porcine cauda equina. Spine (Phila Pa 1976) 1990;15:416-9.

29. Kobayashi S, Suzuki Y, Meir A, Al-Khudairi N, Nakane T, Hayakawa K. Circulatory dynamics of the cauda equina in lumbar canal stenosis using dynamic contrast-enhanced magnetic resonance imaging. Spine J 2015;15:2132-41.

30. Eppenberger P, Andreisek G, Chhabra A. Magnetic resonance neurography: diffusion tensor imaging and future directions. Neuroimaging Clin N Am 2014;24:245-56. 